\title{
Accounting Education in an Action-Based Learning Environment: Lessons Learned
}

\author{
Paulino L. Silva \\ ISCAP, Portugal \\ paulino@iscap.ipp.pt
}

\author{
J. Freitas Santos \\ ISCAP, Portugal \\ jfsantos@iscap.ipp.pt
}

\author{
Isabel Vieira \\ ISCAP, Portugal \\ mivieira@iscap.ipp.pt
}

\begin{abstract}
In the context of the Bologna Declaration a change is taking place in the teaching/learning paradigm. From teaching-centered education, which emphasizes the acquisition and transmission of knowledge, we now speak of learning-centered education, which is more demanding for students. This paradigm promotes a continuum of lifelong learning, where the individual needs to be able to handle knowledge, to select what is appropriate for a particular context, to learn permanently and to understand how to learn in new and rapidly changing situations.

One attempt to face these challenges has been the experience of ISCAP regarding the teaching/learning of accounting in the course Managerial Simulation. This paper describes the process of teaching, learning and assessment in an action-based learning environment. After a brief general framework that focuses on education objectives, we report the strengths and limitations of this teaching/learning tool. We conclude with some lessons from the implementation of the project.
\end{abstract}

\section{Introduction}

In an era of increasing specialization and professionalization higher education in accounting and management face intense criticism for failing to impact useful competencies to students and lead graduates to proper jobs. This criticism comes from students, employers, alumni, business leaders and opinion makers. The focus of the criticism seems to be of the inadequacy of the vocational competencies accounting graduates possess.

In the context of the Bologna Declaration, a change is taking place in the teaching/learning paradigm. From teaching-centered education which emphasizes the acquisition and transmission of knowledge, we now focus more on learning-centered education, while put the onus on students to develop the capacity to learn. In the end, this new paradigm promotes a continuum of lifelong learning, in which the individual needs to be able to handle knowledge, to update it, to select what is appropriate for a particular context, to learn permanently and to understand how to learn in new and rapidly changing situations.

One attempt to satisfy the criticism of stakeholders and face the challenges of the Bologna Paradigm has been the experience developed in ISCAP (Instituto Superior de Contabilidade e Administração do Porto) regarding the teaching/learning of accounting. The course, named Simulação Empresarial (Managerial Simulation, MS), begun in the second semester of 2002/2003, offered in the first cycle degree of accounting and administration.

This course was chosen as the focus of this paper for three reasons. First, Managerial Simulation can be used to evaluate higher levels of learning, such as integrating material from several sources, critically evaluating data, contrasting and comparing information. Second, the course offers a wide range of teaching techniques (tutorials, exercise classes, problem-solving sessions, work based practice, classroom based practical classes, etc.) administered by a supervisor and several instructors according to educational objectives. Third, the assessment of the course involves more than testing for cognitive achievement (work placement reports or diaries, financial analysis, professional portfolios, fieldwork reports). It also includes the evaluation of attitudes (performance of skills while being observed) and communication skills (oral presentations).

The paper is organized as follows. The second section provides a general framework that focuses on general and specific competencies, teaching techniques, learning activities and modes of 
assessment in the context of the Bologna Process. The third section describes the MS course and the process of teaching, learning and assessment. The fourth section reports the methodology used, followed by the results of a questionnaire and the correspondent analysis. The paper concludes with some recommendations.

\section{Business Education in the Context of the Bologna Process}

Like other professions, business is essentially a human activity that calls upon the syllabus of many academic courses, such as management, accounting, marketing, finance, mathematics, economics or sociology. However, business education too often forgets that students are not merely data collectors; they are data users and integrators. Thus, what they need from educators is help in understanding how to interpret data and guidance from experienced teachers in making decisions in the absence of clear information. After all, any low-level administrator can make sound decisions when all the facts are available; having the courage to take a shot in the dark is one of the hallmarks of leadership. If the purpose of business education is to develop executives (leaders), then the school must have expertise in more than just data collection. The best classroom experiences are those in which teachers with broad perspectives and diverse skills analyze cases that have seemingly straightforward technical challenges and then gradually peel away the layers to reveal hidden strategic, economic, competitive, human, and political complexities - all of which must be plumbed to reach truly effective business decisions (Bennis and O'Toole, 2005).

Therefore, experience is vital to business education, as most issues facing managers are questions of judgment that are made with messy, incomplete, and incoherent data. What looks like a straightforward financial decision - say, to cut costs by relocating a service centre - often has implications for marketing, sales, manufacturing, and motivation.

One of the key issues in business education that arose from the Bologna Process was the debate about how to teach, about the learning activities and assessment methods that would best allow students to obtain the intended competencies. These competencies are understood as including knowing and understanding (the capacity to know and understand theoretical knowledge), knowing how to act (the practical and operational application of knowledge in real-life situations), knowing how to behave (values as an integral part of living with others in society). The level to which a person is capable of performing a combination of attributes (knowledge and its application, attitudes, skills, responsibilities) is called a competency.

Tuning Project II (González and Wagenaar, 2005) identified thirty generic competencies. From these, eight were selected for different areas of education: i) capacity for analysis and synthesis; ii) capacity for applying knowledge in practice; iii) basic general knowledge in the field of study; iv) information management skills; v) interpersonal skills; vi) ability to work autonomously; vii) elementary computer skills; viii) research skills. Then, specific competencies were also identified for business education (first cycle): i) analytical capacity - this implies abilities in identifying the business environment, assumptions and objectives of the firm, and the resources and competencies required to solve the problems; ii) choice capacity - this means being able to make decisions or to argue and defend a choice, being aware of the risks and uncertainties associated with making choices, and stating the implications and consequences of the choice made; iii) implementation capacity - this requires abilities in planning and organizing, creating the right setting, managing change, argumentation and follow-up, understanding and awareness, and leadership skills.

In the accounting profession, according to American Institute of Certified Public Accountants (AICPA, 2006), individuals must be able to use strategic and critical approaches to decision-making, considering issues, identifying alternatives, and choosing and implementing solutions to deliver services and provide value. Other functional competencies of an accounting professional include: risk analysis (audit and business risk) and control; ability to apply different measurement criteria; communication skills to report findings or recommendations; research skills to access relevant guidance or other information; necessary skills to use technology tools effectively and efficiently. As the United Nations Conference on Trade and Development (UNCTAD, 2003: 4) states: "it is not sufficient for persons aspiring to become professional accountants to possess only theoretical knowledge. Accountants must be able to apply theoretical knowledge in practical, real-life situations by obtaining, analyzing, interpreting, synthesizing, evaluating and communicating information".

After presenting the competencies for the professional accountant we ask which appropriate modes of teaching and which learning activities might best foster those competencies - how do we assess them.

A wide range of teaching techniques could be used, depending on the focus of the teaching and the intended learning outcomes for the students. From the classical lecture (more or less interactive), to the more technology-oriented methods (e/b learning), we can mention other techniques such as seminars (small 
group teaching), work-based practice, demonstration classes, workshops (classroom-based practical classes) and problem-solving sessions.

Students are also required to do some learning activities like conducting searches for relevant materials in libraries and on-line; surveying literature; asking questions and communicating answers to others using a variety of media; working under time constraints; leading or being useful members of teams; chairing and participating usefully in meetings; preparing and making oral presentations, either in groups or individually; practising professional skills, working with other students to co-produce a report/answer to a problem, research and write papers or reports.

To complete the cycle of learning one must look at how students' achievement of learning outcomes is assessed. Different modes of assessment could be used, such as tests of knowledge and skill, oral presentations, analyses of texts and data, performance of skills while being observed (work placements), professional portfolios, fieldwork reports or diaries. Written examinations can take the format of essays, multiple choice questions, problemsolving exercises, analyses of cases, or literature reviews. Oral examinations can take the form of oral questioning or demonstration of a practical skill.

To provide some evidence about these issues, the next section describes the teaching, learning and assessment processes of the MS course at ISCAP.

\section{Teaching Accounting in an Action- Based Learning Environment: the Course of Managerial Simulation (MS)}

\subsection{Background}

ISCAP is one of the biggest Portuguese accounting schools. It is one hundred and five years old and has nearly four thousand students (First Cycle). Although ISCAP provides five different degrees (Accounting and Administration, International Business, Marketing, Secretariat, and Business Communication), the majority of students (almost 70\%) are enrolled in Accounting and Administration.

In February 2003, a MS course was introduced. This change occurred in a proactive manner. First, to be a future member of the Portuguese Chamber of Certified Accountants (CTOC), it is compulsory to complete an internship in an accounting firm or a module of simulation integrated in the management/accounting study programs. Second, accounting education had been orientated to basic competencies that do not have sufficient value for the accounting professional. Third, some old-fashion accounting concepts that were taught had no practical use. In the same stream of other higher education institutions, ISCAP has changed the way accounting and business was taught.

To implement this course, it was necessary to buy a lot of material resources, especially hardware and software. Two classrooms were equipped with computers, printers, scanners, telephones, and other equipment. Other rooms, for administrative purposes, were also equipped with hardware and software. An integrated management system software and a relational database were bought to build a wide network environment. In the very beginning it was necessary to have a lot of human resources, as the project began with more than a thousand students.

Since the start of the project, companies have had an important role as sponsors. There is a partnership between ISCAP and external entities in the project. ISCAP has been performing the new role of a higher education institution as stated by Etskowitz and Leydesdorff (2000).

\subsection{Objectives}

The main objective of the MS course is to overcome the weaknesses of traditional education, by giving a practical view of professional activity and preparing students for the real business world. This aim is consistent with some studies that proclaim action-based learning (e.g. Adler and Milne, 1997; Fiet, 2001). Another objective of the MS course is to enable students to apply knowledge previously obtained in other courses (e.g. Financial Accounting, Tax Law, Management). Still, there have been some difficulties, because the study program was not totally prepared to facilitate that purpose.

A new teaching method was used in ISCAP with the implementation of the MS course. Students have to know, not only traditional and theoretical concepts, but also how to apply them in a practical situation. Moreover, students must be prepared for lifelong learning during their professional careers. The use of an integrated management information system, by students, prepares them for high-level business and management careers.

\subsection{Resources}

In the beginning, seventeen teachers, and administrative and technical staff were involved because of the large number of students. The background of the teachers was mainly in management and accounting areas. The teachers' role in the classroom was essentially to explain and support students' activities. All activities were planned and available for students with two classes in advance. Additionally, some administrative tasks were done by teachers, such as, preparing the 
environment, providing some special services (banks, insurance companies, public administration, etc.) to students' companies. Administrative and technical staff maintained the operation of the whole system.

In terms of material resources there were two classrooms with a maximum capacity of sixty students each. A planning and an administrative room were also provided. The planning room is used for teachers' work and for meetings. The administrative room is divided into two parts; one for computer servers and all the needed material to keep the system running, and the other for students. Students are allowed to practice into the information system, whenever they want in order to improve their performance during the classes.

\subsection{Environment}

With advances in technology, the problems of information scarcity and access have diminished considerably. For an accounting professional, it is very important to choose the relevant information. In addition to several important competencies, an accounting professional should have the right information systems to manage all information. Consequently, the accountant's role is increasingly important for organisations, as their work has a widened perspective. Participation in the decisionmaking process and the knowledge of how companies work are some examples of a new accounting professional's activities.

The MS course aimed to alert students that all of these changes (in the world, and consequently in the accountant's role) are not a future trend but a fact of life. Therefore, to stimulate lifelong learning, students are requested to read and analyse business magazines and newspapers so that they can make some comments about the possible consequences for them. Portuguese and English were used in this task. Additionally, students have to apply their broadened knowledge in MS courses. The first example is the process of a company formation, which allows students to apply law concepts. Other examples of activities are inventory management, human resources management, financial management, and information systems management. All these activities are possible without any risk, as students perform in a "protected" or risk-free environment.

In a classroom, there are several groups of students. Each group has three or four students that represent a company. This procedure is intended to provide a teamwork skill, as advocated by other authors (Prichard et al., 2006). The students' companies have to do exactly what a real company does, especially concerning deadlines. All real events that have a deadline, such as taxes and payment of salaries, must be accomplished by students' companies. Each students' company has a different activity, providing a diversified market. Other special entities, such as business associations, insurance companies, banks, rental companies, public administration, leasing and factoring companies, etc., are managed by teachers (ISCAP, 2005a).

Students' companies are the main entities of the simulation environment, as they are the focus of the new methodology. They cooperate and compete among themselves. All tasks completed by students provide a substantial volume of information for the decision-making process. In spite of the fact that students have a business plan with some constraint costs, there are some decisions they have to make. For example, some questions like 'how many products should be ordered?'; 'what to do if there is too much, or not enough money in the bank account?' should be answered by students.

Figure 1: The Model of MS

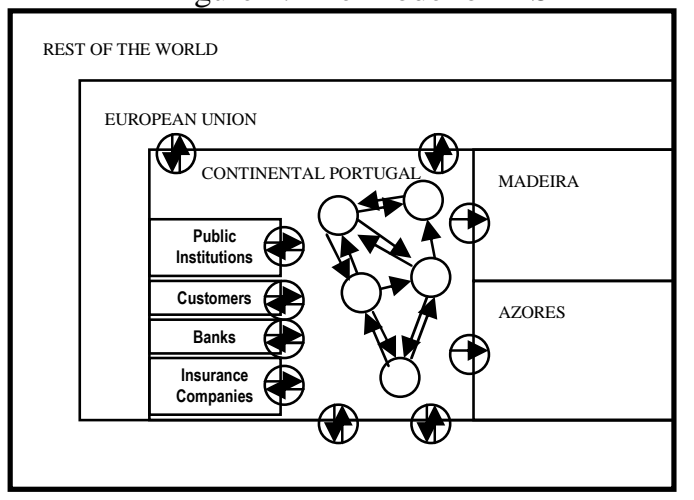

Figure 1 shows the business environment framework used in the MS course. Circles represent entities that interact with each other. Students' companies are represented by the circles located in Continental Portugal. The other circles represent external entities, such banks, insurance companies, public administration institutions, customers and suppliers from Portugal Islands Azores and Madeira and even foreign companies from European Union and from the Rest of the World. All of these external entities have commercial and non-commercial relations with students' companies.

Students write a report about a company's performance during the semester and present it orally, at the end of the semester. Students' companies have to comply with quality standards in order to be certified by ISO 9001-2000. As the real world does provide much uncertainty and imply the satisfaction of deadlines, some tasks are done under pressure. To balance the system, constraints must be respected by all students' firms (ISCAP, 2005a).

\subsection{Assessment System}

The introduction of the MS course required special assessment: a group evaluation component of 
$65 \%$, and an individual evaluation part of $35 \%$. Group evaluation is divided into continuous evaluation, and summative evaluation. Continuous evaluation consists of class assessment, and summative evaluation encompasses assessment of physical files and of the final report. Individual evaluation takes into account participation, behavior, and the report's oral presentation. All these assessment procedures are completed by teachers, helped by the information system. Each semester the number of classes must be the same for all students. If a teacher cannot attend a class, another teacher will replace him/her. Table 1 presents the components of the assessment system.

Table 1 - Components of MS Assessment

\begin{tabular}{|c|c|c|}
\hline Description & $0-100$ & $0-20$ \\
\hline Continuous Ev. & $48,75 \%$ & 9,75 \\
\hline $\begin{array}{l}\text { Summative } \\
\text { (Files) }\end{array}$ & $9,75 \%$ & 1,95 \\
\hline $\begin{array}{l}\text { Summative } \\
\text { (Report) }\end{array}$ & $6,50 \%$ & 1,30 \\
\hline Behavior & $10,50 \%$ & 2,10 \\
\hline Participation & $10,50 \%$ & 2,10 \\
\hline $\begin{array}{c}\text { Oral } \\
\text { Presentation }\end{array}$ & $14,00 \%$ & 2,80 \\
\hline TOTAL & $100 \%$ & 20,00 \\
\hline
\end{tabular}

\section{Methodology}

Data used comes from a survey administrated to students of MS in June 2006 and June 2007. A random sample of 283 students of MS was questioned about the interest of MS course and the implications for their professional life. A significant percentage of the students $(53,1 \%)$ have no professional experience. The age of participants ranges from less than 23 years $(55,5 \%)$, to $23-30$ years $(31,4 \%)$ and more than 30 years $(13,1 \%)$. The sample is skewed in terms of gender, with over $70 \%$ being female. After preliminary questions regarding age, gender and professional experience, the questionnaire asked respondents to focus on the interest of the course (Q1), if the course was a useful way to learn $(\mathrm{Q} 2)$, if the simulation method was better than the traditional one (Q3), if the course wasn't useful (Q4), if the course provided practical competencies to management (Q5), if the course was necessary (Q6), if the competencies developed along the course will be useful in the future (Q7), if during the course the cooperation among students went well (Q8), if during the course the students developed teamwork spirit (Q9) and if during the course the works and reports demanded by teachers developed writing skills (Q10). A 5 steps scale was used for the answers: $1=$ totally disagree up to $5=$ totally agree.

\section{Results and analysis}

As we can see in Table 2, the younger students gave more importance to the course than older students. The only exception is question 8 where older students seem more cooperative. The same is true for students that have no professional experience, which tend to see this course as a complement to their more theoretical or scientific education. In general, males considered the course better than females, except when we question cooperative and work group competencies. Question 4 positively tests for the veracity of the answers.

Table 2 - Descriptive Statistics (mean)

\begin{tabular}{|l|c|c|c|c|c|c|c|}
\hline & & Age & & Exp & & Gen & der \\
\hline $\mathbf{Q}$ & $<\mathbf{2 3}$ & $\begin{array}{c}\mathbf{2 3 -} \\
\mathbf{3 0}\end{array}$ & $\mathbf{3 0}$ & No & Yes & $\mathbf{F}$ & $\mathbf{M}$ \\
\hline $\mathbf{1}$ & 4,06 & 3,72 & 3,71 & 4,08 & 3,72 & 3,88 & 4,01 \\
\hline $\mathbf{2}$ & 3,91 & 3,63 & 3,66 & 3,92 & 3,63 & 3,75 & 3,89 \\
\hline $\mathbf{3}$ & 3,94 & 3,70 & 3,83 & 3,97 & 3,71 & 3,81 & 3,93 \\
\hline $\mathbf{4}$ & 1,49 & 1,63 & 1,94 & 1,47 & 1,73 & 1,63 & 1,52 \\
\hline $\mathbf{5}$ & 3,64 & 3,37 & 3,34 & 3,62 & 3,39 & 3,51 & 3,53 \\
\hline $\mathbf{6}$ & 4,03 & 3,85 & 3,83 & 4,12 & 3,75 & 3,88 & 4,11 \\
\hline $\mathbf{7}$ & 4,06 & 3,84 & 3,80 & 4,12 & 3,77 & 3,88 & 4,12 \\
\hline $\mathbf{8}$ & 4,23 & 4,23 & 4,43 & 4,18 & 4,34 & 4,33 & 4,09 \\
\hline $\mathbf{9}$ & 4,31 & 4,01 & 4,29 & 4,27 & 4,16 & 4,27 & 4,10 \\
\hline $\mathbf{1 0}$ & 3,58 & 3,33 & 3,49 & 3,58 & 3,39 & 3,50 & 3,47 \\
\hline
\end{tabular}

Factor analysis (Table 3) tells us that the interest of the course for MS students could be divided in three factors. The first aggregates the pedagogical methods used that are very different from the classical method (lectures). The second indicates that competencies in general given by this course are important for students. The third specifies the more valuable competencies for students, e.g. cooperation, work group and writing skills. In brief, we can say that MS is characterized by: i) innovative pedagogical methods; ii) is competency-oriented and iii) develop cooperative, work group and writing skills.

Table 3 - Factor Analysis (Rotated MatrixVarimax)

\begin{tabular}{|l|l|l|}
\hline Variables & Component 1 & Component 2 \\
\hline Q1 & $\mathbf{0 , 8 5 5}$ & 0,225 \\
\hline Q2 & $\mathbf{0 , 8 3 7}$ & 0,245 \\
\hline Q3 & $\mathbf{0 , 7 4 8}$ & 0,217 \\
\hline Q4 & $-0,691$ & 0,045 \\
\hline Q5 & $\mathbf{0 , 7 2 4}$ & 0,270 \\
\hline Q6 & $\mathbf{0 , 8 4 5}$ & 0,186 \\
\hline Q7 & $\mathbf{0 , 8 5 0}$ & 0,216 \\
\hline Q8 & 0,008 & $\mathbf{0 , 8 8 4}$ \\
\hline Q9 & 0,254 & $\mathbf{0 , 8 7 8}$ \\
\hline Q10 & 0,438 & $\mathbf{0 , 5 4 7}$ \\
\hline
\end{tabular}

Cumulative variance explained by three factors: $68,524 \%$ 


\section{Recommendations and Conclusion}

ISCAP started in February 2003 with a MS course in the accounting and administration study program. The Bologna Process was implemented in the academic year of 2007/08. MS is a good example of a new way of teaching, learning and evaluation processes.

Some recommendations can be emphasised about how to increase students' cognitive learning:

Encourage and recognize students' work, being alert to nonverbal clues, and occasionally comment positively on students' work (but do not do it every time);

Instructors should act as facilitators covering theoretical topics when needed and helping students remember or research previous concepts;

Provide a summary and/or conclusion at the end of a class or group of classes.

Other recommendations to increase the affective aspects of learning can be considered:

Know your students' (motivations, profile, etc.);

Be sensitive to students' feelings;

Challenge the students, but do not threaten them;

Deal with conflicts (do not ignore them).

Knowing some strengths and limitations of MS can help instructors make better decisions about whether or not to use this simulation environment. However, MS is not only a teaching tool, as learning activities and an independent assessment system has also been developed to provide an integrated approach.

As previously described, MS is flexible enough to design assignments and learning environments that enhance higher levels of cognitive learning (application, analysis, synthesis) and increase the likelihood that students will be able to address the open-ended problems they will face in their professional roles.

\section{References}

[1] R.W. Adler, and M.J. Milne, "Improving the Quality of Accounting Students' Learning through Action-Oriented Learning Tasks", Accounting Education, 6(3), 1997, pp. 191-215.

[2] H. Etzkowitz, and L. Leydesdorff, "The Dynamics of Innovation: from National Systems and "Mode 2" to a Triple Helix of University-Industry-Government Relations", Research Policy, 29, 2000, pp. 109-123.

[3] J.O. Fiet, "The Theoretical Side of Teaching Entrepreneurship", Journal of Business Venturing, 16(1), 2001, pp. 1-24.

[4] ISCAP, "Managerial Simulation: Support Book", ISCAP, 28, 2005.

[5] ISCAP, "Regulamento de Inscrição, Frequência e Avaliação das Disciplinas de Simulação Empresarial", ISCAP, 2005.

[6] J.S. Prichard, et al. "Team-Skills Training Enhances Collaborative Learning", Learning and Instruction, 16, 2006, pp. 256-265.

[7] UNCTAD (United Nations Conference on Trade and Development), "Revised Model Accounting Curriculum (MC)", TD/B/COM.2/ISAR/21, 2003. 